\title{
Development and use of a framework for characterising computer models of silvoarable economics
}

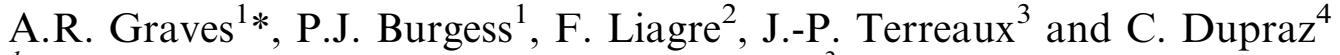 \\ ${ }^{1}$ Cranfield University, Silsoe, Bedford MK45 4DT, UK; ${ }^{2}$ Assemblée Permanente des Chambres d'Agriculture, \\ 9 Avenue Georges V, 75008 Paris, France; ${ }^{3}$ Cemagref, Montpellier, France; ${ }^{4}$ Institut National de la Recherche \\ Agronomique, 2 Place Viala, 34060 Montpellier, France; *Author for correspondence (e-mail: \\ a.r.graves@cranfield.ac.uk; phone: +44-1525-863107; fax: +44-1525-863344)
}

Agroforestry Systems (2005) 65:53-65

DOI 10.1007/s10457-004-5545-0

The wrong affiliation was shown for the fourth author in the original. 